\title{
Exercise and dyspnoea in COPD
}

\author{
P.M.A. Calverley
}

ABSTRACT: Dyspnoea provoked either by exercise or during a disease exacerbation is one of the most feared symptoms of the chronic obstructive pulmonary disease (COPD) patient. It contributes to impaired quality of life and patients who are more limited by exertional dyspnoea are more likely to die. The physiological mechanisms responsible for these two outcomes vary in different settings, but in both situations, changes in the resting lung volume and increased activation of the respiratory muscles relative to their maximum capacity is the final common pathway.

Although increased metabolic carbon dioxide production from weak or poorly conditioned muscles is an important cofactor, most patients limited by exertional dyspnoea exhibit dynamic hyperinflation that parallels their symptom intensity. This results from the longer respiratory time constant of the lungs in COPD and coexisting expiratory flow limitation during tidal breathing. The response of the chest wall muscles to this change in lung volume is variable: most patients with more severe COPD allow chest wall volume to increase, while others try to defend chest wall volume. The latter is not a good breathing strategy as the patient's exercise capacity is very limited.

Treatment with bronchodilators reduces operating lung volumes and delays the time until tidal volume is mechanically limited by the inspiratory reserve volume. Breathing oxygen and heliox gas mixtures further increases exercise endurance and slows the rate at which end-expiratory lung volume increases.

During exacerbations there is a consistent increase in end-expiratory lung volume and this parallels the reduction in forced vital capacity. This suggests that gas trapping due to airway closure is the main mechanism involved here, although changes in lung volume still track the symptomatic improvement in dyspnoea reported by patients both as the episode resolves and after nebulised bronchodilator treatment.

KEYWORDS: Bronchodilator, chronic obstructive pulmonary disease, dynamic hyperinflation, exacerbation, exercise performance, heliox

xercise limitation and the breathlessness that accompanies it are key features of chronic obstructive pulmonary disease (COPD). The inability to exercise as much as unaffected contemporaries is one of the principal worries of patients who have symptomatic COPD [1]. As a result, patients' lives are more limited than would otherwise be the case. In a large international telephone survey, $60 \%$ of patients reported that they were greatly restricted in their ability to undertake sports or recreational activities and 55\% had similar limitations to normal physical exertion. Problems limited family activities in $29 \%$ of affected people [2]. The presence of impaired exercise performance is one of the major determinants of overall reduction in health status [3], and limitation of daily activities at home is an independent predictor of the likelihood of having a COPD exacerbation [4]. COPD patients undertake less physical activity than agematched controls and spend more time sitting or lying down when at home [5]. Moreover, maximum exercise capacity is now known to predict prognosis, whether this is assessed using tests like the 6-min walking distance [6] or by more sophisticated physiological measurements made while using a cycle ergometer [7].

Breathlessness on exertion is an integral part of the problem. Most patients exercise until they can no longer tolerate their breathlessness. This point is often determined by mechanical factors (discussed further later), but other variables, particularly the patient's mood and expectations of exercise, will also determine how much they exercise, at least in self-paced walking tests [8]. Despite being a less "objective" measurement, it is still useful to evaluate breathlessness in COPD. In populations of patients, the severity of exercise limitation that they report can be classified simply using a modified Medical Research Council Breathlessness Scale. In a 5-yr followup study of 227 patients in Japan, the severity of breathlessness was an appreciably better predictor of the patient's subsequent survival than was the severity of airflow obstruction, which was
CORRESPONDENCE

Division of Infection and Immunity

Clinical Sciences Centre

University Hospital Aintree

Lower Lane

Liverpool L9 7AL

UK

Fax: 441515295888

E-mail: pmacal@liverpool.ac.uk 
assessed with forced expiratory volume in one second (FEV1) at the start of the study [9]. The information provided by breathlessness scoring appears to be complimentary to that derived from self-paced exercise testing, and these properties have been utilised to develop what appears to be the most powerful prognostic scoring system thus far reported. This is the so-called BODE index, based on body mass index (B), obstruction (O), dyspnoea (D) and exercise (E), the latter two being assessed by the modified Medical Research Council scale and a 6-min self-paced walking test, respectively. These variables can be combined within several broad categories to produce a composite score that clearly distinguishes longerterm survival in patients with COPD more reliably than the use of currently reported spirometric classification systems [10]. Thus far, the relative importance or weight of each of these four variables in a given population has not been reported and may well vary across a range of populations studied. Nonetheless, the general principle that exercise and breathlessness are valuable for more than just symptomatic reasons now appears to be generally accepted.

COPD exacerbations are an equally important outcome and this topic has been reviewed previously in detail [11]. Patients are just as concerned about the possibility of uncontrolled attacks of breathlessness as they are about dyspnoea on exertion [1], where exacerbations contribute significantly to impaired health status in COPD [12]. Patients who report taking less exercise and who go out less in cold weather exacerbate more frequently [13]. However, not all exacerbations are accompanied by increased breathlessness [14], and whether different processes produce consistently different symptomatology has still to be resolved.

The present article will consider how breathlessness is related to exercise performance in stable COPD and how new methods of studying and/or predicting lung volumes during exercise can help to inform this relationship. Far fewer data are available regarding lung mechanics and, specifically, operating lung volume in unstable COPD, but recent data suggest that hyperinflation may be an important mechanism driving symptoms in this setting.

\section{PHYSIOLOGICAL FACTORS LIMITING EXERCISE CAPACITY IN COPD}

A large number of potentially important mechanisms may operate singly, but most commonly in combination, to limit exercise performance in patients with COPD. Their relative importance is likely to vary with the severity of the airflow obstruction. The symptoms that people report as limiting their exercise capacity are also variable. In a large unselected population of patients undergoing cardiorespiratory exercise testing, a majority of patients said that they stopped exercising during cycle exercise because of leg fatigue or a combination of leg fatigue and dyspnoea [15]. It was proposed that factors that determine peripheral skeletal muscle performance, such as oxygen delivery during exercise and the presence of peripheral muscle weakness [16], were at least as important as variables related to lung mechanics in determining exercise performance in COPD. These observations stimulated considerable debate, although more recent reports in smaller populations of wellcharacterised patients with very severe COPD indicate that, in most cases, breathlessness limited exercise rather than leg fatigue [17]. An explanation for this discrepancy has now been provided in a mechanistic study in which exercise during treadmill walking was compared with that during cycle exercise [18]. This clearly showed that different types of exercise tests lead to different limitations, even in people with quite severe COPD. More specifically, patients who exercise on a bicycle are more likely to develop peripheral muscle fatigue, which can be objectively demonstrated, than is the case when patients are exercising during walking on the level. Thus, the interpretation of exercise limitation and its related breathlessness depend on the type of test carried out, and it is evident that not all tests produce the same answers.

Despite the frequent observation that many patients with moderate-to-severe COPD have falls in oxygen saturation when they exercise, there is little evidence that the severity of oxygen desaturation itself determines exercise performance. Oxygen desaturation can worsen after a bronchodilator is given, and yet the patient can undertake more exercise subsequently [19]. Although oxygen desaturation is abolished when supplementary oxygen is given, the improvement in exercise performance is more likely to reflect a reduction in minute ventilation and, possibly, a reduction in skeletal muscle lactate production, than the degree to which desaturation is prevented [20]. Indeed, the majority of data now point to COPD patients being limited by mechanical factors during exercise, although this interplay between primary pulmonary and extrapulmonary causes for exercise limitation continues to be debated. As already noted, in an individual patient, many factors may be operative, not least the presence of relevant comorbidities that affect cardiac function, something which certainly influences oxygen delivery to exercising muscle.

\section{MECHANICAL DETERMINANTS OF EXERCISE IMPAIRMENT IN COPD}

For many years, it has been clear that mechanical constraints to breathing set a ceiling on exercise performance in patients with all forms of persistent airflow obstruction. Indeed, the FEV1 that is now used to characterise expiratory airflow obstruction was originally developed as an "indirect maximum breathing capacity" measurement and, using a variety of formulae, the maximum voluntary ventilation of an individual can be estimated from the FEV1 [21]. This is clearly relevant, as the maximum ventilation attainable by a patient with airflow obstruction will be reduced, partly because of the lengthened mechanical time constant of the respiratory system in these patients, and also because the respiratory muscles themselves operate at a mechanical disadvantage in patients whose endexpiratory lung volume (EELV) is increased. Important insights into dynamic factors that cause further deterioration in lung mechanics during exercise resulted from a series of experiments in the 1990s [22, 23], although historically the first observations in this field had been made some $25 \mathrm{yrs}$ previously [24]. There is now no doubt that patients with severe and very severe COPD do not reduce their EELV in the same way as healthy normal subjects, but instead exhibit dynamic hyperinflation (DH) with a rise in EELV throughout exercise [25]. The presence of airflow obstruction appears to be crucial here, although loss of elastic recoil in some fit elderly individuals is associated with a tendency to $\mathrm{DH}$ at the end of exercise but not during it [26]. This problem is discussed in 
detail in one of the accompanying articles in this issue of the European Respiratory Review [27]. It is sufficient to say that there is abundant evidence that $\mathrm{DH}$ is highly prevalent in COPD, is more likely to occur as the airflow obstruction progresses and can be demonstrated even after self-paced corridor walking [28].

Most reports on DH are made in the setting of cycle ergometry with an externally imposed incremental workload. In these circumstances, it is clear that neuromechanical dissociation is an important factor producing breathlessness during exercise that is most marked towards the end of exercise when the endinspiratory lung volume comes to within a few hundred millilitres of the total lung capacity (TLC) [29], a change that is also seen in severely breathless patients admitted to hospital reporting breathlessness at rest [30]. Measurements of EELV are normally made by asking the patient to perform an inspiratory capacity (IC) manoeuvre, and good data have been taken during exercise that show the TLC to be apparently constant. Thus, changes in IC reflect changes in the operating lung volumes and overcome the otherwise complex issue of having to measure TLC during exercise and then subtract the independently measured IC from this. This undoubtedly reduces the reported error in these measurements. The tendency to develop DH of the lungs reflects the onset of expiratory flow limitation (EFL), which mechanically limits the ability of the patient to obtain a higher tidal volume at the original operating lung volume. Recently, developments in measurement techniques have added to the ability to study this problem and also the way in which the whole of the chest wall muscles are activated during exercise. These data indicate that patients use a range of strategies rather than simply allowing their lung volumes to change when they exercise.

\section{NEW METHODS FOR ASSESSING FLOW LIMITATION AND CHEST WALL VOLUMES}

The assessment of EFL is complex and, until recently, has been extremely difficult to carry out at rest, let alone during exercise [31]. This situation was greatly improved by the development of the negative expiratory pressure method, which provides a global assessment of EFL in the lungs by comparing a normal tidal breath with one immediately afterwards in which a negative pressure is applied [32]. If expiratory flow increases over the tidal volume range during the second expiration, then it is reasonable to assume that EFL was not present in the first. This relatively new method overcomes a range of complex technical issues that have bedevilled the evaluation of flow limitation in patients with COPD. Studies have shown that patients with resting EFL are more likely to develop DH when they exercise, whereas in those who do not, the ratio of the FEV1 to forced vital capacity (FVC) is a better predictor of their exercise capacity [33]. Likewise, the behaviour of patients who do and do not have EFL at rest predicts their subsequent response to bronchodilator drugs [34]. There are some data to show that patients who are not flow limited at rest can develop EFL when they exercise, which would be an important predictor of performance, although establishing this is technically complex, mainly because of the higher respiratory frequencies during exercise [35].

An alternative way of assessing the presence of EFL has recently been reported, this time by defining a threshold at which global flow limitation occurred based on the withinbreath change in respiratory system reactance that happens when airways become flow limited [36]. This method involves more complex instrumentation, although it has the advantage that it is likely to be reduced in size and automated in the near future. It allows flow limitation to be assessed in multiple consecutive breaths. It is clear that in people who are close to the threshold for the onset of flow limitation, testing one breath may lead to a positive result for flow limitation, whereas a breath two or three breaths later would lead to a different classification. This is a result of dynamic regulation of EELV. This process may be important in limiting conditions during exercise, when the patient can choose a pattern of hyperinflation or instead adopt a different breathing strategy that may be more physiological but less adapted to sustaining exercise. Applying these new noninvasive methods should lead to better understanding of this problem.

\section{OPTOELECTRONIC PLETHYSMOGRAPHY}

During the last few years, for the first time, it has become possible to noninvasively measure the absolute volume enclosed by the chest wall through the technique of optoelectronic plethysmography (fig. 1), which uses the reflection of infrared light from the series of 89 markers positioned over the chest wall to accurately compute its volume. Absolute volumes are difficult to estimate for practical reasons but the change in volume can be accurately recorded and broken down into regions of interest, particularly the movement of the pulmonary and abdominal ribcage and the abdominal compartmental volume, which reflects the action of the diaphragm and the abdominal muscles. In healthy subjects, this method gives excellent agreement with lung volume measurements derived from recordings at the mouth made at rest and during exercise $[37,38]$. When healthy subjects exercised to their maximum performance breathing through a Starling resistor circuit, most of them maintained a relatively constant end-expiratory chest wall volume, although some tried to behave as they normally would and reduced EELV, which was an energetically counterproductive strategy [39].

Measurements in COPD patients using optoelectronic plethysmography at rest have shown good agreement between measured volumes at the mouth but, like the patients breathing through the resistive circuit, the behaviour during exercise is different. In initial studies of COPD patients performed by the present author and co-workers, most patients allowed their chest wall volume to rise during incremental exercise, although a significant minority were able to maintain constant lung volumes, even at the cost of developing very high intraabdominal pressures and stopping after shorter periods of exercise than those who allowed hyperinflation to occur [40]. The behaviour of the abdominal compartment, and hence the relationship between diaphragm activation and activation of the abdominal wall muscles during exercise, appears to be crucial. In a recent study, the present author and co-workers found that patients who improved their exercise performance after nebulised salbutamol allowed their resting EELVs to fall and then continued to show a pattern of hyperinflation, albeit at a lower absolute volume [41]. This is very similar to behaviour reported in previous studies that measured dynamic lung volume changes after use of a bronchodilator. 


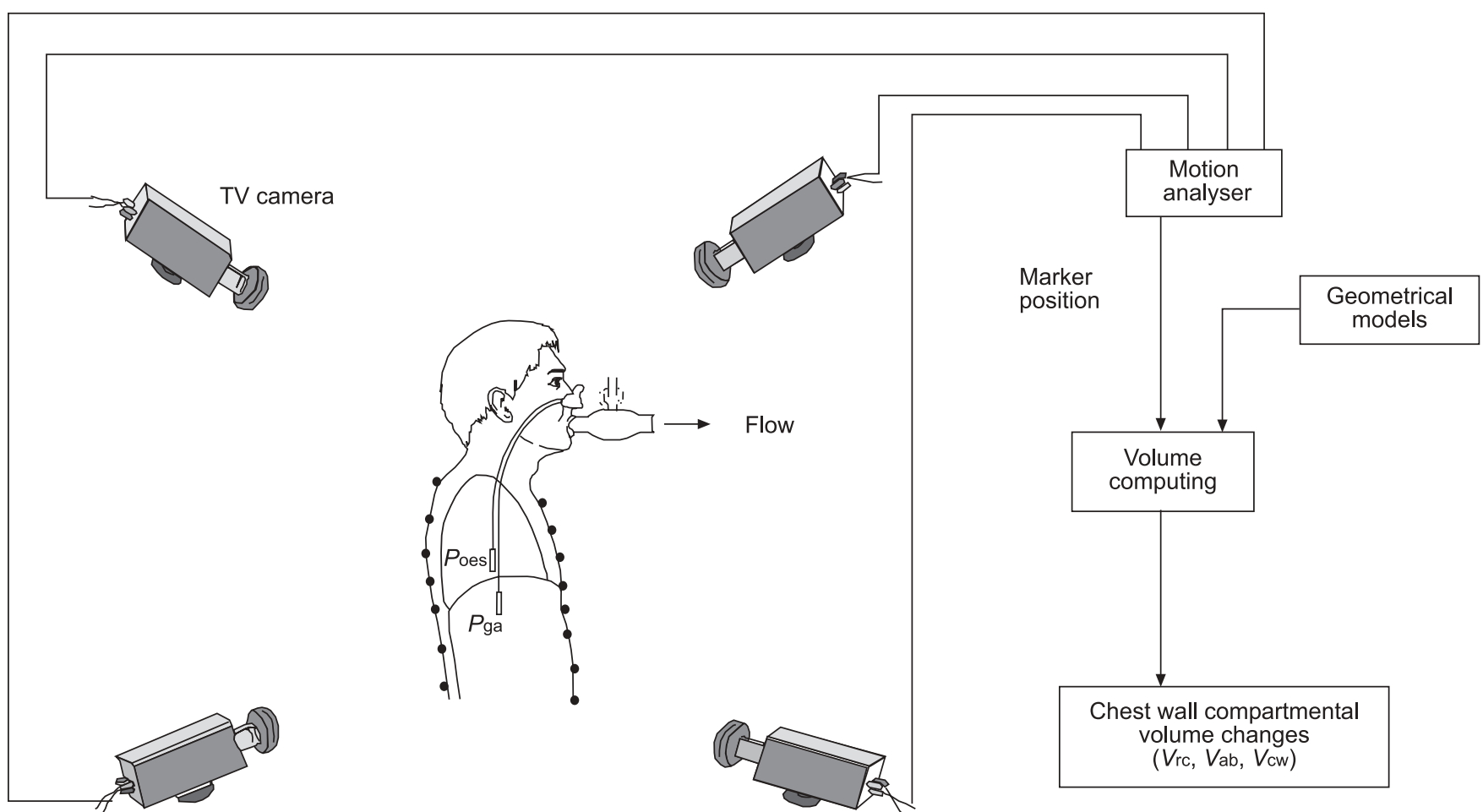

FIGURE 1. Schematic representation of the system for acquiring quantitative volume measurements noninvasively during exercise. Data obtained from the motion analysis software can be compared with volumes measured at the mouth and the degree of intrathoracic gas compression and blood shift calculated. Poes: oesophageal pressure; Pga: gastric pressure; Vrc: ribcage volume; Vab: abdominal compartmental volume; $V_{c w}$ : chest wall volume.

In contrast, individuals whose exercise performance deteriorated changed their breathing strategy during exercise to try to further reduce their end-expiratory chest wall volume when they exercised after the bronchodilator, which in their case led to a shortening of total exercise time (fig. 2). These data help explain results in the literature in which some patients improve lung function after use of a bronchodilator but do not necessarily improve their functional performance [42]. Other patterns of chest wall behaviour during exercise have been reported recently, with some patients maintaining their chest wall volume at a relative constant until late in exercise [43]. How these patients are affected by other interventions, e.g. pulmonary rehabilitation, has yet to be determined.

\section{EXERTION AND BREATHLESSNESS}

As previously noted, breathlessness is a major factor limiting exercise capacity in COPD patients. Exercise testing provides a powerful way to study the sensation of breathlessness and the factors that determine its intensity, since a given stimulus can be repeatedly applied in a standardised fashion and the patient's subjective response can be evaluated. Drugs that improve exercise performance will normally reduce the intensity of breathlessness relative to the same stimulus, i.e. the isotime value, before the drug was administered [44]. This provides good evidence that breathlessness during exercise is largely determined by mechanical factors and the changes in the activation of abdominal and diaphragmatic muscles during exercise provide further support for this [40, 45]. Nonbronchodilator intervention can also reduce exertional breathlessness, the most widely used being ambulatory oxygen. Good data showing that oxygen is associated with less breathlessness for a given level of exercise performance exist in laboratory exercise and field exercise testing [46]; this is thought to be due to reduced peripheral chemoreceptor drive, as well as a reduction in lactate production [47]. Recently, studies in which the inspired gas density has been reduced by substituting nitrogen with helium have also reported a reduced intensity of breathlessness relative to air breathing data [48]; this has been confirmed during endurance shuttle walk testing in a large population of COPD patients [49]. In the latter study, there was evidence of an interaction between reduced gas density breathing and relative hyperoxia, although this was seen only in patients with more severe airflow obstruction. Studies of improving physical exercise performance with pulmonary rehabilitation also show a reduction in $\mathrm{DH}$ relative to prerehabilitation data, although this too is likely to reflect a lower metabolic carbon dioxide production post-exercise for the same external work [50].

Thus, in a variety of settings using a range of interventions, it is clear that breathlessness during exercise in COPD is determined by mechanical factors, and it can be therapeutically useful to improve these by a number of different and potentially additive interventions. However, exercise is a very specific circumstance in which the intensity of breathlessness increases because the metabolic load and consequently the respiratory drive to breathe also rise as exercise progresses. This can be seen even during self-paced walking tests [51]. The same is not necessarily true when exercise stops, although in clinical practice many patients often take their bronchodilators to relieve breathlessness when they stop exercising; some 

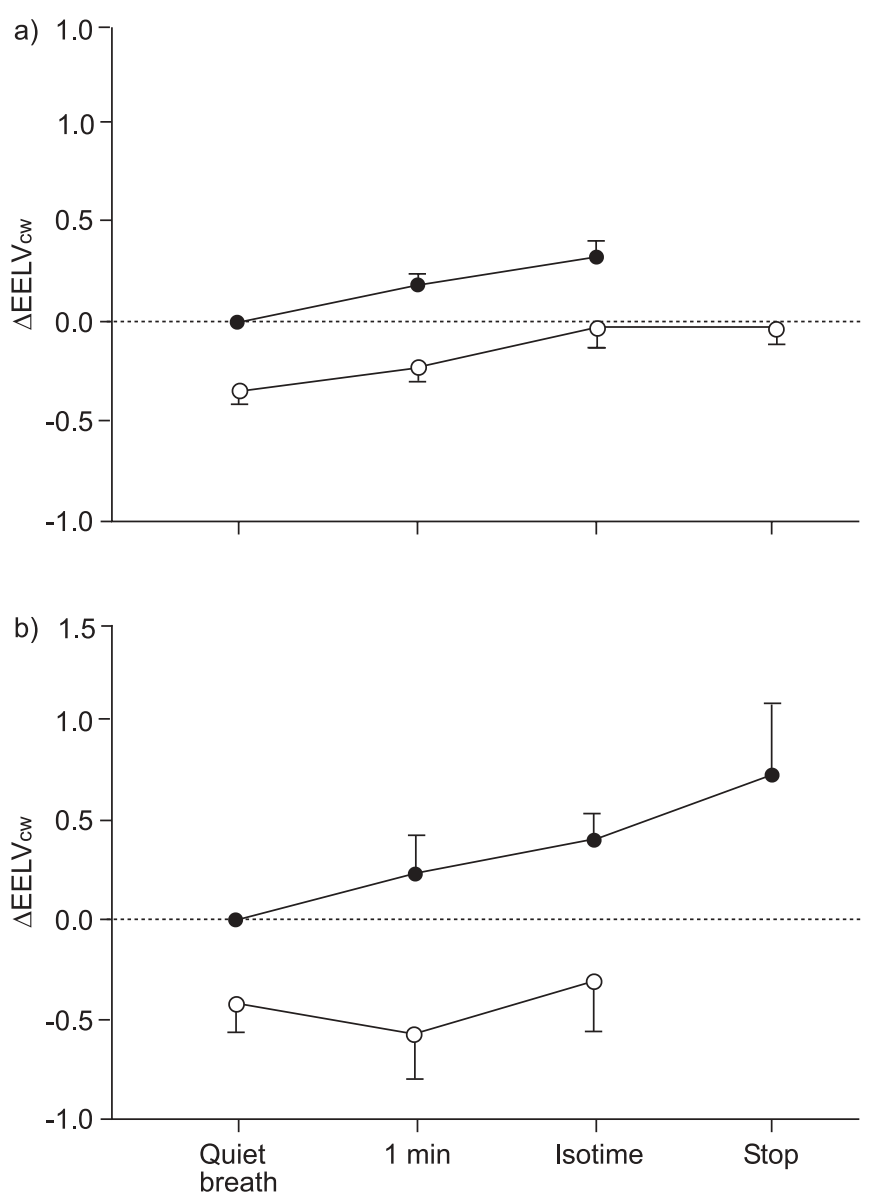

FIGURE 2. Change in total end-expiratory chest wall volume ( $\left.\Delta E E L V_{c w}\right)$ for a) improvers and b) nonimprovers during endurance exercise after nebulised saline

(-) or $5 \mathrm{mg}$ of nebulised salbutamol $(\bigcirc)$ in patients with stable chronic pulmonary obstructive disease separated by their subsequent change in exercise performance after salbutamol. The patients in whom exercise performance increased (a) showed dynamic hyperinflation before and after exercise but operated at a lower lung volume after the bronchodilator. Those whose performance worsened (b) tried to maintain their chest wall volume constant after the bronchodilator and stopped sooner

physicians advocate using oxygen as a way of reducing ventilatory drive when the patient is no longer capable of performing. A recent study in which the intensity of breathlessness was carefully standardised by exercise testing before patients were randomised to treatment with air or oxygen has cast doubt on whether this is a sensible approach [52]. In that study, in which almost all patients showed $\mathrm{DH}$ during exercise, oxygen breathing during the recovery period was associated with a small but significant reduction similar to exercise stopped in the degree of DH. However, the intensity of breathlessness and the rate of recovery of breathlessness were not different in patients who received oxygen in air; neither did it matter whether the patients were instrumented and breathing through a mouthpiece or simply breathing oxygen from a face mask. These data demonstrate that although mechanical factors can be very important against a background of rising ventilatory drive, other factors, particularly repayment of oxygen debt when exercise ceases, can be more important.

\section{LUNG VOLUMES DURING EXACERBATIONS OF COPD}

Investigating the relationship between operating lung volumes and dyspnoea during exercise is a relatively straightforward problem once appropriate methods of measurement have been developed. Patients can attend when clinically stable and motivated, and perform tests using accepted measures of performance, such as peak oxygen consumption or heart rate. Retesting the patient after an intervention allows determination of whether treatment modifies operating volumes and provides a mechanistic explanation for its effect.

Studying patients during an exacerbation is much more difficult and is essentially opportunistic. Moreover, the ability of the patient to satisfactorily perform respiratory manoeuvres may be significantly less than when they are well, while their reluctance to return for restudy is greater. These logistical constraints have, until recently, severely limited knowledge about lung mechanics in spontaneously breathing COPD patients during a period of exacerbation. In the 1980s and 1990s, studies in the intensive care unit in ventilated COPD patients with hypercapnic respiratory failure defined the importance of intrinsic positive end-expiratory pressure (PEEPi) as an important and previously unsuspected inspiratory threshold load that significantly increased the elastic work of breathing [53]. Despite much discussion about how to measure this variable in the face of continuing abdominal muscle activation [54], there was widespread agreement that PEEPi arose because of incomplete lung emptying during spontaneous or artificially ventilated breathing and, as such, these data prefigured much of the subsequent discussion about $\mathrm{DH}$ during exercise in stable COPD [31]. However, assessing breathlessness in this clinical situation is difficult when patients are either intubated or the effect of sedation is wearing off; thus, the relationship of these pressure-related measurements to operating lung volume has proven difficult to interpret.

Two recent reports in nonhypercapnic patients have provided more direct information about how operating lung volumes change as an exacerbation resolves [30,55]. The numbers of subjects studied are still modest (20 and 22, respectively), with significant numbers not completing all of the measurement protocol. The majority of patients in the Canadian study were managed as outpatients, while all the British patients were initially admitted to hospital. Spirometric lung function was not as impaired as might be expected in either study, with a mean FEV1 of $41 \%$ predicted in Canada and $47 \%$ pred in the UK, although these measurements were made on the day of presentation after treatment commenced. STEVENSON et al. [30] followed all patients daily for 3 days and up to discharge, with a final review at 6 weeks, while PARKER et al. [55] saw the patient at presentation, and then 14, 30 and 60 days later. Both groups measured spirometry; in the UK patients, this was measured both pre- and postbronchodilator.

The change in FEV1 was small over time in both studies, amounting to some $200 \mathrm{~mL}$ over the $6-8$ week recovery period. The FEV1/FVC ratio did not change in either trial, nor did it change acutely when nebulised bronchodilators were administered, suggesting that the increase in FEV1 was because lung volume fell rather than because of a change in airways resistance. This was supported by the constant respiratory 
system resistance measured by impulse oscillometry in the UK patients. In contrast, both studies showed significant improvements in IC, which was measured using plethysmography in the Canadian study. The mean respiratory system reactance became less negative during recovery, which might reflect the reduction in lung volume at which it was measured but could also reflect a reduction in the degree of EFL and airway closure [36]. Resting breathlessness fell as hyperinflation lessened, regardless of whether it was assessed by the Chronic Respiratory Questionnaire or a modified Borg scale. Patients in whom the Borg scale did not change showed no improvement in lung volume in the British study, a finding that was not confirmed in the small number of Canadian patients in whom this happened. An acute improvement in FEV1 postbronchodilator was not seen initially but became more obvious over time. In contrast, a significant increase in IC was seen in all the bronchodilator tests, as was an acute reduction in reported dyspnoea.

These studies suggest that in nonhypercapnic COPD exacerbations, the change in lung volume is the most important variable associated with a reduction in dyspnoea, and is responsive to therapy and improves as the episode resolves. These changes may reflect airway closure and gas trapping during the exacerbation and the Canadian patients showed a significant improvement in oxygen saturation breathing air compatible with better ventilation/perfusion matching over time. Both trials found the respiratory frequency to be relatively constant, which would favour a change in static rather than dynamically regulated lung volume in this setting. Whether comparable changes in volume during exercise and exacerbation would produce equivalent degrees of breathlessness awaits further study.

\section{CONCLUSIONS}

Exercise limitation and its attendant increase in breathing difficulty remains at the heart of much of the clinical management of stable chronic obstructive pulmonary disease, while improvement in the management and prevention of exacerbations are urgently needed. Advances in physiological measurement have now made it possible to record changes in lung volumes in a standardised way that can be applied in multiple laboratories and thus address important clinical issues [56]. Insights into the activation of the chest wall muscles compliment these observations and should help to explain some of the individual variability in performance that patients report. It must also be remembered that factors other than pulmonary disease determine exercise performance, not least the daily levels of activity and coexisting cardiac problems. Evaluating chronic obstructive pulmonary disease patients in terms of their exercise capacity is likely to remain a multidisciplinary task, but one in which treatment can be extremely rewarding. Applying these complex methodologies to more acutely ill patients during exacerbations will be an even greater challenge, but one in which the gains in understanding should prove to be just as rewarding.

\section{REFERENCES}

1 van der MT, Willemse BW, Schokker S, Ten Hacken NH, Postma DS, Juniper EF. Development, validity and responsiveness of the Clinical COPD Questionnaire. Health Qual Life Outcomes 2003; 1: 13.

2 Rennard S, Decramer M, Calverley PM, et al. Impact of COPD in North America and Europe in 2000: subjects' perspective of Confronting COPD International Survey. Eur Respir J 2002; 20: 799-805.

3 Jones PW. Health status measurement in chronic obstructive pulmonary disease. Thorax 2001; 56: 880-887.

4 Soler-Cataluna JJ, Martinez-Garcia MA, Roman SP, Salcedo E, Navarro M, Ochando R. Severe acute exacerbations and mortality in patients with chronic obstructive pulmonary disease. Thorax 2005; 60: 925-931.

5 Garcia-Aymerich J, Farrero E, Felez MA, Izquierdo J, Marrades RM, Anto JM. Risk factors of readmission to hospital for a COPD exacerbation: a prospective study. Thorax 2003; 58: 100-105.

6 Pinto-Plata VM, Cote C, Cabral H, Taylor J, Celli BR. The 6min walk distance: change over time and value as a predictor of survival in severe COPD. Eur Respir J 2004; 23: 28-33.

7 Oga T, Nishimura K, Tsukino M, Sato S, Hajiro T. Analysis of the factors related to mortality in chronic obstructive pulmonary disease: role of exercise capacity and health status. Am J Respir Crit Care Med 2003; 167: 544-549.

8 Morgan AD, Peck DF, Buchanan DR, McHardy GJ. Effect of attitudes and beliefs on exercise tolerance in chronic bronchitis. BMJ (Clin Res Ed) 1983; 286: 171-173.

9 Nishimura K, Izumi T, Tsukino M, Oga T. Dyspnea is a better predictor of 5-year survival than airway obstruction in patients with COPD. Chest 2002; 121: 1434-1440.

10 Celli BR, Cote CG, Marin JM, et al. The body-mass index, airflow obstruction, dyspnea, and exercise capacity index in chronic obstructive pulmonary disease. $N$ Engl J Med 2004; 350: 1005-1012.

11 Rennard SI, Farmer SG. Exacerbations and progression of disease in asthma and chronic obstructive pulmonary disease. Proc Am Thorac Soc 2004; 1: 88-92.

12 Spencer S, Calverley PM, Burge PS, Jones PW. Impact of preventing exacerbations on deterioration of health status in COPD. Eur Respir J 2004; 23: 698-702.

13 Donaldson GC, Wilkinson TM, Hurst JR, Perera WR, Wedzicha JA. Exacerbations and time spent outdoors in chronic obstructive pulmonary disease. Am J Respir Crit Care Med 2005; 171: 446-452.

14 Seemungal TA, Donaldson GC, Bhowmik A, Jeffries DJ, Wedzicha JA. Time course and recovery of exacerbations in patients with chronic obstructive pulmonary disease. Am J Respir Crit Care Med 2000; 161: 1608-1613.

15 Killian KJ, LeBlanc P, Martin DH, Summers E, Jones NL, Campbell EJM. Exercise capacity and ventilatory, circulatory, and symptom limitation in patients with chronic airflow limitation. Am Rev Respir Dis 1992; 146: 935-940.

16 Gosselink R, Troosters T, Decramer M. Peripheral muscle weakness contributes to exercise limitation in COPD. Am J Respir Crit Care Med 1996; 153: 976-980.

17 Man WD, Soliman MG, Gearing J, et al. Symptoms and quadriceps fatigability after walking and cycling in chronic obstructive pulmonary disease. Am J Respir Crit Care Med 2003; 168: 562-567.

18 Pepin V, Saey D, Whittom F, LeBlanc P, Maltais F. Walking versus cycling: sensitivity to bronchodilation in chronic 
obstructive pulmonary disease. Am J Respir Crit Care Med 2005; 172: 1517-1522.

19 Spence DP, Hay JG, Carter J, Pearson MG, Calverley PM. Oxygen desaturation and breathlessness during corridor walking in chronic obstructive pulmonary disease: effect of oxitropium bromide. Thorax 1993; 48: 1145-1150.

20 O'Donnell DE, D'Arsigny C, Webb KA. Effects of hyperoxia on ventilatory limitation during exercise in advanced chronic obstructive pulmonary disease. Am J Respir Crit Care Med 2001; 163: 892-898.

21 Dillard TA, Hnatiuk OW, McCumber TR. Maximum voluntary ventilation: Spirometric determinants in chronic obstructive pulmonary disease patients and normal subjects. Am Rev Respir Dis 1993; 147: 870-875.

22 O'Donnell DE, Webb KA. Exertional breathlessness in patients with chronic airflow limitation. The role of lung hyperinflation. Am Rev Respir Dis 1993; 148: 1351-1357.

23 O'Donnell DE, Lam M, Webb KA. Measurement of symptoms, lung hyperinflation, and endurance during exercise in chronic obstructive pulmonary disease. Am J Respir Crit Care Med 1998; 158: 1557-1565.

24 Potter WA, Olafsson S, Hyatt RE. Ventilatory mechanics and expiratory flow limitation during exercise in patients with obstructive lung disease. J Clin Invest 1971; 50: 910-919.

25 O'Donnell DE, Revill SM, Webb KA. Dynamic hyperinflation and exercise intolerance in chronic obstructive pulmonary disease. Am J Respir Crit Care Med 2001; 164: 770-777.

26 Johnson BD, Reddan WG, Seow KC, Dempsey JA. Mechanical constraints on exercise hyperpnea in a fit aging population. Am Rev Respir Dis 1991; 143: 968-977.

27 O'Donnell DE, Laveneziana P. Physiology and consequences of lung hyperinflation in COPD. Eur Respir Rev 2006; 15: 61-67.

28 Marin JM, Carrizo SJ, Gascon M, Sanchez A, Gallego B, Celli BR. Inspiratory capacity, dynamic hyperinflation, breathlessness, and exercise performance during the 6minute-walk test in chronic obstructive pulmonary disease. Am J Respir Crit Care Med 2001; 163: 1395-1399.

29 O'Donnell DE, Voduc N, Fitzpatrick M, Webb KA. Effect of salmeterol on the ventilatory response to exercise in chronic obstructive pulmonary disease. Eur Respir J 2004; 24: 86-94.

30 Stevenson NJ, Walker PP, Costello RW, Calverley PM. Lung mechanics and dyspnea during exacerbations of chronic obstructive pulmonary disease. Am J Respir Crit Care Med 2005; 172: 1510-1516.

31 Calverley PM, Koulouris NG. Flow limitation and dynamic hyperinflation: key concepts in modern respiratory physiology. Eur Respir J 2005; 25: 186-199.

32 Koulouris NG, Valta P, Lavoie A, et al. A simple method to detect expiratory flow limitation during spontaneous breathing. Eur Respir J 1995; 8: 306-313.

33 Diaz O, Villafranca C, Ghezzo H, et al. Breathing pattern and gas exchange at peak exercise in COPD patients with and without tidal flow limitation at rest. Eur Respir J 2001; 17: 1120-1127.

34 Boni E, Corda L, Franchini D, et al. Volume effect and exertional dyspnoea after bronchodilator in patients with
COPD with and without expiratory flow limitation at rest. Thorax 2002; 57: 528-532.

35 Koulouris NG, Dimopoulou I, Valta P, Finkelstein R, Cosio MG, Milic-Emili J. Detection of expiratory flow limitation during exercise in COPD patients. J Appl Physiol 1997; 82: 723-731.

36 Dellaca RL, Santus P, Aliverti A, et al. Detection of expiratory flow limitation in COPD using the forced oscillation technique. Eur Respir J 2004; 23: 232-240.

37 Aliverti A, Cala SJ, Duranti R, et al. Human respiratory muscle actions and control during exercise. J Appl Physiol 1997; 83: 1256-1269.

38 Cala SJ, Kenyon CM, Ferrigno G, et al. Chest wall and lung volume estimation by optical reflectance motion analysis. $J$ Appl Physiol 1996; 81: 2680-2689.

39 Iandelli I, Aliverti A, Kayser B, et al. Determinants of exercise performance in normal men with externally imposed expiratory flow limitation. J Appl Physiol 2002; 92: 1943-1952.

40 Aliverti A, Stevenson N, Dellaca RL, Lo MA, Pedotti A, Calverley PM. Regional chest wall volumes during exercise in chronic obstructive pulmonary disease. Thorax 2004; 59: 210-216.

41 Aliverti A, Rodger K, Dellaca RL, et al. Effect of salbutamol on lung function and chest wall volumes at rest and during exercise in COPD. Thorax 2005; 60: 916-924.

42 Man WD-C, Mustfa N, Nikoletou D, et al. The effect of salmeterol on respiratory muscle activity during exercise in poorly reversible COPD. Thorax 2004; 59: 471-476.

43 Vogiatzis I, Georgiadou O, Golemati S, et al. Patterns of dynamic hyperinflation during exercise and recovery in patients with severe chronic obstructive pulmonary disease. Thorax 2005; 60: 723-729.

44 O'Donnell DE, Lam M, Webb KA. Spirometric correlates of improvement in exercise performance after anticholinergic therapy in chronic obstructive pulmonary disease. Am J Respir Crit Care Med 1999; 160: 542-549.

45 Hawkins P, Johnson LC, Nikoletou D, et al. Proportional assist ventilation as an aid to exercise training in severe chronic obstructive pulmonary disease. Thorax 2002; 57: 853-859.

46 Somfay A, Porszasz J, Lee SM, Casaburi R. Dose-response effect of oxygen on hyperinflation and exercise endurance in nonhypoxaemic COPD patients. Eur Respir J 2001; 18: 77-84.

47 O'Donnell DE, Bain DJ, Webb KA. Factors contributing to relief of exertional breathlessness during hyperoxia in chronic airflow limitation. Am J Respir Crit Care Med 1997; 155: 530-535.

48 Palange P, Valli G, Onorati P, et al. Effect of heliox on lung dynamic hyperinflation, dyspnea and exercise endurance capacity in COPD patients. J Appl Physiol 2004; 97: 1637-1642.

49 Laude EA, Duffy NC, Baveystock C, et al. The effect of helium and oxygen on exercise performance in COPD: a randomised crossover trial. Am J Respir Crit Care Med 2006; 173: 865-870.

50 Porszasz J, Emtner M, Goto S, Somfay A, Whipp BJ, Casaburi R. Exercise training decreases ventilatory requirements and exercise-induced hyperinflation at submaximal 
intensities in patients with COPD. Chest 2005; 128: 2025-2034.

51 Troosters T, Vilaro J, Rabinovich R, et al. Physiological responses to the 6-min walk test in patients with chronic obstructive pulmonary disease. Eur Respir J 2002; 20: 564-569.

52 Stevenson NJ, Calverley PM. Effect of oxygen on recovery from maximal exercise in patients with chronic obstructive pulmonary disease. Thorax 2004; 59: 668-672.

53 Gottfried SB, Rossi A, Higgs BD, et al. Noninvasive determination of respiratory system mechanics during mechanical ventilation for acute respiratory failure. Am Rev Respir Dis 1985; 131: 414-420.
54 Zakynthinos SG, Vassilakopoulos T, Zakynthinos E, Roussos C. Accurate measurement of intrinsic positive end-expiratory pressure: how to detect and correct for expiratory muscle activity. Eur Respir J 1997; 10: 522-529.

55 Parker CM, Voduc N, Aaron SD, Webb KA, O'Donnell DE. Physiological changes during symptom recovery from moderate exacerbations of COPD. Eur Respir J 2005; 26: 420-428.

56 Maltais F, Hamilton A, Marciniuk D, et al. Improvements in symptom-limited exercise performance over $8 \mathrm{~h}$ with once-daily tiotropium in patients with COPD. Chest 2005; 128: $1168-1178$. 